\title{
Cerebral oximetry monitoring in non-intubated patients undergoing endoscopic retrograde cholangiopancreatography under propofol- induced sedation: a prospective observational study
}

\author{
Magdalini Velegraki ${ }^{a}$, Maria Manolaraki ${ }^{b}$, Irene Chainaki ${ }^{\mathrm{b}}$, Emmanouil Vardas ${ }^{a}$, Maria Petrodaskalakic, \\ Nikolaos Androulakis ${ }^{b}$, Chrysanthi Georgakaki ${ }^{b}$, Evangelia Lazanaki ${ }^{b}$, Gregorios Chlouverakis ${ }^{d}$, \\ Gregorios A. Paspatis ${ }^{\mathrm{a}}$ \\ Venizeleion General Hospital; University Hospital of Heraklion; School of Medicine, University of Crete, Heraklion, \\ Crete, Greece
}

Abstract

\begin{abstract}
Background Prolonged propofol-induced deep sedation increases the risk for sedationrelated complications. Cerebral oximetry enables prompt assessment of tissue oxygenation by demonstrating the regional hemoglobin oxygen saturation $\left(\mathrm{rSO}_{2}\right)$ of the cerebral cortex. This study aimed to: evaluate cerebral oxygenation under deep sedation during an endoscopic retrograde cholangiopancreatography (ERCP) procedure; determine the cerebral desaturation event (CDE) rate; and assess the predictive capacity of CDEs for sedation-related complications.
\end{abstract}
Methods All consecutive patients who underwent ERCP between September and December 2019 were included prospectively. Propofol monotherapy was used and sedation level was assessed using the bispectral index (BIS). The target level of sedation was deep sedation, defined by BIS values 40-60. Participants were monitored with arterial blood gas analysis and INVOS 5100C cerebral oximeter. $\mathrm{RSO}_{2}$ values were registered prior to sedation (baseline value), every 5 min during the sedation period and at recovery of consciousness. BIS values were recorded simultaneously. CDE was defined as a drop $>10 \%$ from individual baseline $\mathrm{rSO}_{2}$.

Results Sixty patients were enrolled. Mean baseline $\mathrm{rSO}_{2}$ was $65.1 \%$ and BIS values ranged from 18 85. No significant correlation was observed between mean $\mathrm{rSO}_{2}$ measurements and mean BIS values throughout the recordings $(P=0.193)$. Data from patients aged $\geq 65$ years were analyzed separately and the results were similar. The $\mathrm{CDE}$ rate was $2.7 \%$, but no $\mathrm{CDE}$ was associated with clinical manifestations. Twelve sedation-related complications occurred without the presence of cerebral desaturation.

Conclusion Cerebral oxygenation remained independent of changes in sedation depth and cerebral oximetry monitoring did not detect complications earlier than standard monitors.

Keywords Cerebral oxygenation, deep sedation, cerebral oximetry, near infrared spectroscopy, ERCP

Ann Gastroenterol 2021; 34 (x): 1-7

Department of a Gastroenterology, Venizeleion General Hospital (Magdalini Velegraki, Emmanouil Vardas, Gregorios A. Paspatis); ${ }^{\mathrm{b}}$ Anesthesiology, Venizeleion General Hospital (Maria Manolaraki, Irene Chainaki, Nikolaos Androulakis, Chrysanthi Georgakaki, Evangelia Lazanaki); ' $Q u$ uality and Research, University Hospital of

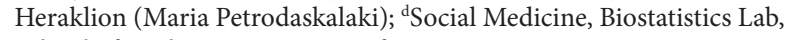
School of Medicine, University of Crete, Voutes University Campus (Gregorios Chlouverakis); Crete, Greece

Conflict of Interest: None

Correspondence to: Gregorios A. Paspatis, MD, PhD, Department of Gastroenterology, Venizeleion General Hospital, Knossou Avenue,

71409, Heraklion, Greece, e-mail address: gpaspatis@gmail.com

Received 22 January 2021; accepted 18 March 2021; published online 3 June 2021

DOI: https://doi.org/10.20524/aog.2021.0637

\section{Introduction}

Endoscopic retrograde cholangiopancreatography (ERCP) is a complex endoscopic procedure used for the treatment of biliopancreatic diseases. Over recent years, moderate sedation (depression of consciousness during which patients respond purposefully to verbal commands) has been associated with high ERCP failure rates due to patient discomfort and premature termination of the procedure [1]. Given the progressively increasing involvement of anesthesia in gastrointestinal endoscopy, deep sedation (depression of consciousness during which patients cannot be aroused easily and maintain their ventilatory function) or general anesthesia (loss of consciousness during which patients are not arousable and require assistance in maintaining a patent airway), 
constitute the most common sedation practices for ERCP procedures at present time.

Despite the fact that deep sedation seems to be a reasonable choice over general anesthesia, interventions required for the treatment of difficult cases and/or the development of procedure-related adverse events may unpredictably prolong the length of ERCP. Furthermore, advances in the field of ERCP, such as the combined use of endoscopic ultrasound in a single session, may also significantly extend the procedural duration. Although propofol presents superior sedative efficacy compared with traditional sedation regimens of benzodiazepines plus opioids [2,3], propofol-induced hypoventilation, hypotension and bradycardia can occur relatively frequently [4]. Moreover, propofol has been particularly associated with episodes of cerebral oxygen desaturation in comparison to other sedative agents [5]. Prolongation of time under deep sedation in ERCP procedures remains a challenge for anesthesiologists, who must provide adequate sedation in spontaneously breathing patients. Therefore, studies oriented towards the evaluation of monitoring techniques to improve the management of patients under deep sedation are worthwhile.

Beside standard monitoring, several methods, including the use of near-infrared spectroscopy (NIRS)based cerebral oximetry, have been proposed over the last years as a means of monitoring cerebral function during anesthesia and surgery [6]. Cerebral oximetry provides instantaneous information about the status of brain perfusion by demonstrating the regional hemoglobin oxygen saturation $\left(\mathrm{rSO}_{2}\right)$ in the frontal cerebral cortex. A decrease in cerebral oxygenation has been associated with events of clinical deterioration, such as arrhythmia, hypotension and hypoxia [7]. Studies have demonstrated a strong agreement between $\mathrm{rSO}_{2}$ and mixed venous oxygen saturation $\left(\mathrm{SvO}_{2}\right)$ in a wide range of clinical settings [8-10]. In many of these observations $\mathrm{SvO}_{2}$ was primarily affected, with minimal or even no effect on arterial oxygen content (i.e. hypoxemia). Low $\mathrm{SvO}_{2}$ values have been shown to be an important warning sign of inadequate systemic oxygen delivery [11]. This suggests that cerebral oximetry may enable prompt assessment of tissue oxygenation, serving as a potential early indicator of sedation-related adverse events.

In this study, our primary aim was to evaluate how cerebral oxygenation is affected by propofol-induced deep sedation during an ERCP procedure. The secondary objectives were to measure the cerebral desaturation event (CDE) rate and assess the predictive capacity of CDEs for sedation-related complications. To the best of our knowledge, there are no existing data on cerebral oximetry monitoring during propofolinduced sedation in spontaneously breathing patients.

\section{Patients and methods}

A total of 60 consecutive patients who underwent therapeutic ERCP procedures between September and December 2019 were prospectively enrolled in the study. No case of exclusion was observed. All procedures were performed under the supervision of an anesthesiologist, who was in charge of the administration and monitoring of sedation, while vital signs were recorded by an independent endoscopy nurse. Deep sedation was the target sedation endpoint and propofol was used as a single sedative agent. The participants' physical status was graded according to the American Society of Anesthesiologists (ASA) Physical Status Classification System (ASA grade) [12]. Exclusion criteria were: (a) age less than 18 years; (b) pregnancy; (c) critical illness (ASA grade V); and (e) history of allergy to propofol or eggs. The study was approved by the scientific committee of our hospital and informed consent was obtained from each patient included in the study.

Depth of sedation was assessed by bispectral index (BIS) monitoring. All patients were continuously monitored using the BIS VIEW device (BIS Monitoring System) and a specific BIS Quatro Sensor (Aspect Medical Systems, Newton, Massachusetts, USA). Overall, BIS values range from $0-100$, and in patients who are awake, a typical BIS score is 90-100 [13]. A BIS value below 60 is associated with a low probability of response to commands. Therefore, in this study, BIS values between 40 and 60 were defined as deep sedation. After basal data had been recorded during full consciousness, supplemental oxygen was administered intranasally $(5 \mathrm{~L} / \mathrm{min})$ and the attending anesthesiologist delivered a $0.5 \mathrm{mg} / \mathrm{kg}$ loading dose of i.v. propofol, followed by continuous infusion with a medical pump, titrated to achieve the level of deep sedation based on BIS readings. All participants were positioned in the left lateral position and continuously monitored with a noninvasive blood pressure device (serial measurements every $3 \mathrm{~min}$ ), electrocardiography, pulse oximetry, and an end-tidal carbon dioxide monitor. In addition, partial pressures of oxygen $\left(\mathrm{PaO}_{2}\right)$ and carbon dioxide $\left(\mathrm{PaCO}_{2}\right)$ in arterial blood gas were measured at 3 time points: (a) prior to propofol administration; (b) intra-procedurally, while patients were intubated with the duodenoscope and deeply sedated (BIS values between 40 and 60); and (c) at recovery of consciousness.

Overall, respiratory depression was defined as a drop of peripheral arterial oxygen saturation $\left(\mathrm{SpO}_{2}\right)$ below $90 \%$ for more than $10 \mathrm{sec}$ and/or lack of respiratory effort for more than $15 \mathrm{sec}$, identified by capnograph $[14,15]$. Hypotension was defined as systolic blood pressure (SBP) $\leq 90 \mathrm{mmHg}$ and bradycardia as a decrease in heart rate (HR) to below 50 beats/min. In case of respiratory depression, the anesthetic protocol included a set of maneuvers and interventions for restoring ventilation (reposition of the airway, jaw thrust or chin lift maneuver, removal of the endoscope, discontinuation of propofol infusion, increase of oxygen flow, bag valve mask ventilation) while maintenance of hemodynamic stability included fluid administration and the use of ephedrine or atropine in case of hypotension or bradycardia, respectively. Patients were moved to the recovery area immediately after the procedure if their vital signs were stable. In the recovery area they were monitored by electrocardiography, pulse oximetry and blood pressure recording in the presence of the anesthesiologist. 


\section{NIRS-based cerebral oximetry monitoring}

All patients were monitored with an $\operatorname{INVOS}^{\mathrm{TM}}$ 5100C cerebral/somatic oximeter (Medtronic, Boulder, Colorado, USA). Two adhesive probes were applied to the skin surface above the frontal lobes and were connected to one INVOS ${ }^{\mathrm{TM}}$ 5100C monitor with 2 channels for bilateral brain monitoring. These probes contain light-emitting diodes and produce 2 wavelengths of near-infrared light (730 and $810 \mathrm{~nm}$ ) capable of tissue penetration through skin and skull to the underlying cerebral region. In this wavelength range, light is partly absorbed when it contacts optical pigments (chromophores) like hemoglobin, and the resultant spectrum changes depending on the oxygenation status of the hemoglobin. A fraction of this light returns towards the surface, is identified by light detectors integrated into the adhesive probes, and the monitor calculates the absolute value of $\mathrm{rSO}_{2}$ using specific algorithms. Normal $\mathrm{rSO}_{2}$ values prior to the induction of sedation range from $60-80 \%$ [16]. We defined specific time points to register $\mathrm{rSO}_{2}$ values, common to all participants: (a) prior to propofol administration (baseline value); (b) just after the induction of deep sedation (first BIS value recorded between 40 and 60) and every 5 min thereafter until the termination of propofol infusion (sedation period); and (c) at recovery of consciousness. At these time points, BIS values were recorded simultaneously. Significant CDE was defined as a decrease in $\mathrm{rSO}_{2}$ value of more than $10 \%$ of baseline value.

\section{Statistical analysis}

Summary descriptive statistics are presented as mean \pm standard deviation for continuous variables and as frequencies (\%) for categorical ones. Paired samples $t$-tests were used to evaluate changes in $\mathrm{PaCO}_{2}$ from baseline to sedation and recovery periods. Associations between continuous variables were assessed graphically with scatterplots and quantified using Pearson's correlation coefficient. All statistical tests were carried out at the 2 -sided 5\% level of significance using IBMSPSS 25.

\section{Results}

Sixty patients were screened (32 females) and none were excluded. Mean (range) age, height, weight, and body mass index (BMI) were 67.9 \pm 17 (27-96) years, $167 \pm 10$ (145-194) $\mathrm{cm}, 76.3 \pm 17.4(45-144) \mathrm{kg}$, and $27.3 \pm 5.0(16.9-41.6) \mathrm{kg} /$ $\mathrm{m}^{2}$, respectively (Table 1 ). Five patients $(8 \%)$ had a medical history of obstructive sleep apnea syndrome. The mean total propofol dose administered was $437.4 \pm 189 \mathrm{mg}$ and the mean duration of sedation was $38.3 \pm 15.8$ (range 15-90) min (Table 1). Despite the fact that deep sedation was the target level of sedation (target range 40-60), BIS values ranged from 18-85 throughout the sedation period. We obtained a total of $480 \mathrm{rSO}_{2}$ measurements per probe. For further analysis, the right-sided and left-sided $\mathrm{rSO}_{2}$ registers for each participant were averaged at every time point of the procedure (mean $\mathrm{rSO}_{2}$ of both hemispheres).

All procedures were therapeutic and were performed by one gastroenterologist. ERCP indications included: choledocholithiasis $(\mathrm{n}=34)$, repeat ERCP for stent removal $(n=10)$, pancreatic cancer $(n=7)$, chronic pancreatitis $(n=2)$, cholangiocarcinoma $(n=2)$, biloma $(n=2)$, unclassified extrahepatic biliary stricture $(n=2)$, and intraductal papillary mucinous neoplasm $(n=1)$. Cholangioscopy was performed in 6 cases and 1 patient underwent electrohydraulic lithotripsy for a tightly impacted stone in the common bile duct. All ERCP procedures were technically successful. The mean (range) duration of the procedure was $41.5 \pm 15.6$ (19-93) min. Difficult cannulation, as defined by the European Society

$\underline{\text { Table } 1 \text { Demographic data of patients, sedation parameters and recovery time }}$

\begin{tabular}{|c|c|c|c|c|}
\hline \multirow[t]{2}{*}{ Characteristics } & \multicolumn{2}{|c|}{ All patients $(n=60)$} & \multicolumn{2}{|c|}{ Patients aged $\geq 65$ years $(n=37)$} \\
\hline & Mean \pm SD (range) & Median (IQR) & Mean \pm SD (range) & Median (IQR) \\
\hline Age (years) & $67.9 \pm 17.0(27.0-96.0)$ & $71.5(26.0)$ & $79.3 \pm 6.9(67.0-96.0)$ & $81.0(10.0)$ \\
\hline \multicolumn{5}{|l|}{ Sex, n (\%) } \\
\hline Male & \multicolumn{2}{|c|}{$28(46.7 \%)$} & \multicolumn{2}{|l|}{$18(48.6 \%)$} \\
\hline Height $(\mathrm{cm})$ & $167.0 \pm 10.0(145.0-194.0)$ & $165.0(17.0)$ & $166.0 \pm 10.0(150.0-194.0)$ & $165.0(17.0)$ \\
\hline Weight (kg) & $76.3 \pm 17.4(45.0-144.0)$ & $75.0(19.0)$ & $73.5 \pm 11.7(45.0-100.0)$ & $75.0(15.0)$ \\
\hline Body mass index $\left(\mathrm{kg} / \mathrm{m}^{2}\right)$ & $27.3 \pm 5.0(16.9-41.6)$ & $27.0(7.1)$ & $26.7 \pm 4.0(16.9-35.3)$ & $27.0(5.9)$ \\
\hline Propofol dose (mg) & $437.4 \pm 189.0(155.0-1180.0)$ & $412.0(202.0)$ & $363.3 \pm 127.8(155.0-689.0)$ & $330.0(211.0)$ \\
\hline Sedation period (min) & $38.3 \pm 15.8(15.0-90.0)$ & $35.0(15.0)$ & $35.3 \pm 14.3(15.0-85.0)$ & $31.0(20.0)$ \\
\hline Range of BIS values (n) & \multicolumn{2}{|c|}{$18-85$} & \multicolumn{2}{|c|}{$20-85$} \\
\hline Time to recovery (min) & $7.8 \pm 3.1(3.0-15.0)$ & $7.0(5.0)$ & $7.9 \pm 3.1(3.0-15.0)$ & $7.0(5.0)$ \\
\hline
\end{tabular}

Results are expressed as frequencies for categorical variables

$I Q R$, interquartile range; SD, standard deviation; BIS, bispectral index 
of Gastrointestinal Endoscopy's Clinical Guidelines [17], was recorded in 8 patients. Post-ERCP pancreatitis, defined according to the revised Atlanta classification [18], occurred in 2 of 60 patients (both cases mild). There were no other immediate complications of the endoscopic procedure (e.g. perforation or bleeding).

Mean (range) $\mathrm{rSO}_{2}$ value at baseline for the 60 patients was $65.1 \pm 11.8 \%$ (37.0-90.5). Fig. 1 illustrates the means of BIS and $\mathrm{rSO}_{2}$ values for the abovementioned fixed time points. We observed that the time course of mean $\mathrm{rSO}_{2}$ values exhibited little variability throughout the sedation period and no significant correlation was demonstrated between the means of $\mathrm{BIS}$ and $\mathrm{rSO}_{2}$ recordings at any time point of the procedure $(P=0.193)$.

The maximum percentage change in $\mathrm{rSO}_{2}$ was calculated as the biggest drop from baseline $\mathrm{rSO}_{2}$ during the sedation period, divided by the baseline value. The correlation between the maximum percentage change in $\mathrm{rSO}_{2}$ and the percentage change in BIS values at the corresponding time point was evaluated and no association was observed ( $\mathrm{r}=-0.086, P=0.44$ ) (Fig. 2).

A further subgroup analysis of the older population (patients aged $\geq 65$ years, $n=37$ ) was performed separately, as this age group has a higher risk of concomitant chronic diseases. Their demographic characteristics are presented in Table 1. The

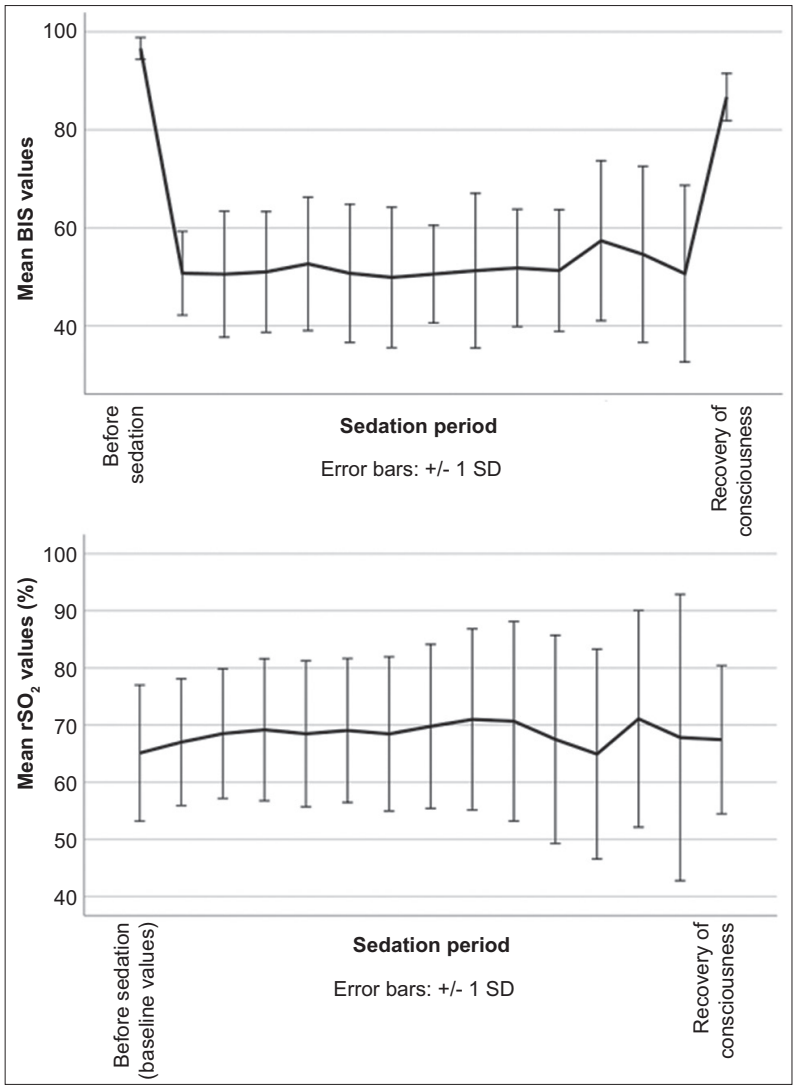

Figure 1 The means of bispectral index (BIS) and regional hemoglobin oxygen saturation $\left(\mathrm{rSO}_{2}\right)$ values. Each tracing represents the grouped measurement for all patients $(n=60)$ at the predefined time points of the procedure

$S D$, standard deviation range of BIS values during the sedation period was 20-85. Fig. 3 shows the means of BIS and $\mathrm{rSO}_{2}$ recordings throughout the predefined time points. Similarly, no significant correlation between them was observed at any time point $(P=0.503)$.

All patients presented a statistically significant increase in $\mathrm{PaCO}_{2}$ following the induction of sedation $(P<0.001)$ and this

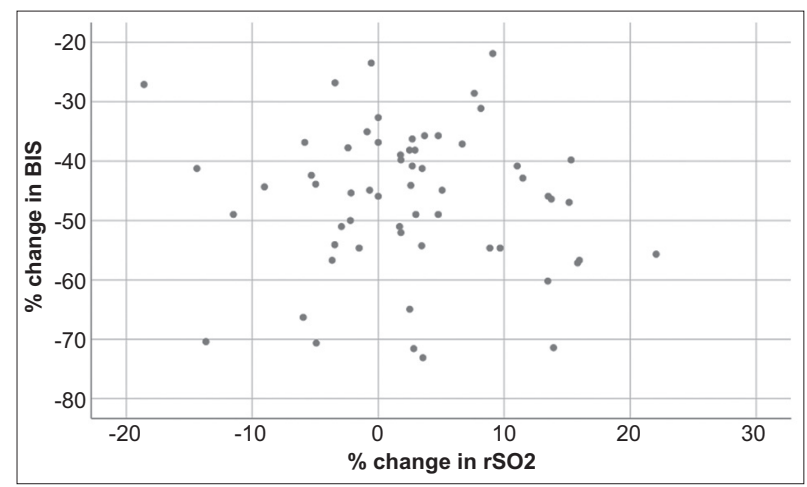

Figure 2 Correlation between the maximum percentage change in regional hemoglobin oxygen saturation $\left(\mathrm{rSO}_{2}\right)$ and the percentage change in bispectral index (BIS) values at the corresponding time point

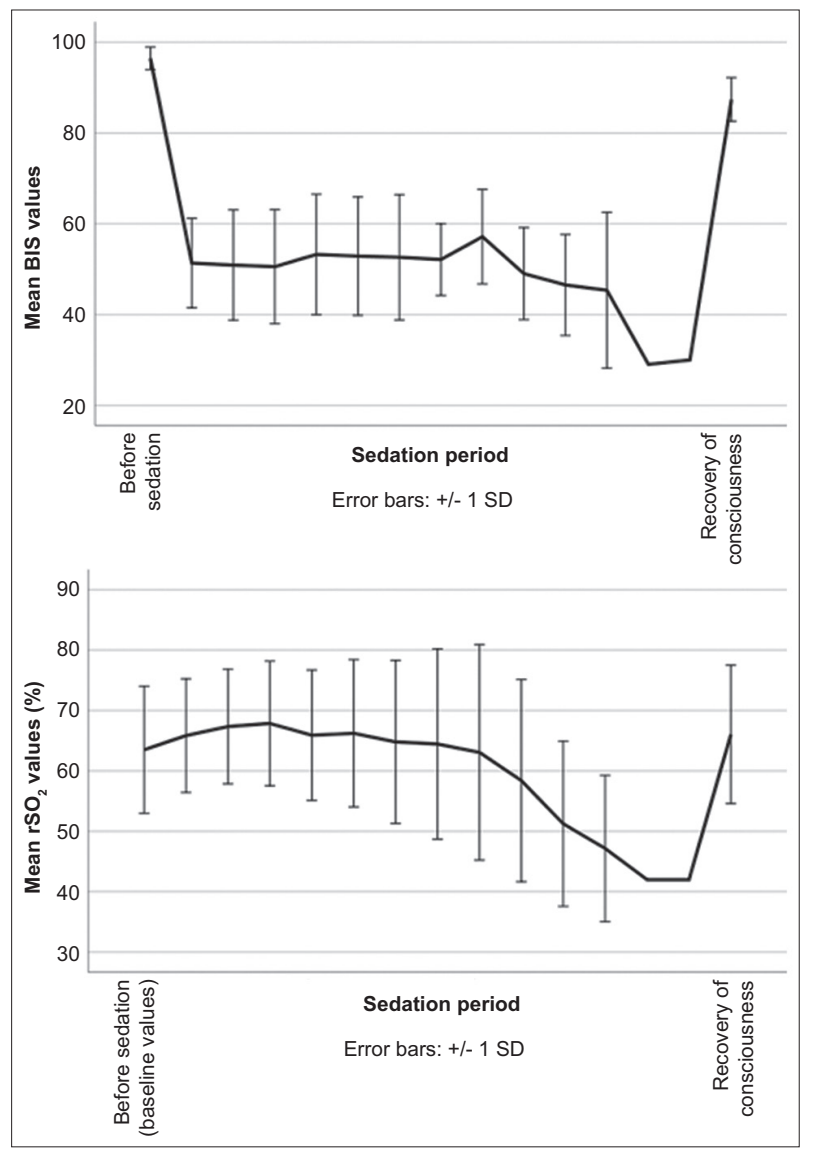

Figure 3 The means of bispectral index (BIS) and regional hemoglobin oxygen saturation $\left(\mathrm{rSO}_{2}\right)$ values. Each tracing represents the grouped measurement for patients aged $\geq 65$ years $(n=37)$ at the predefined time points of the procedure $S D$, standard deviation 
increase persisted until recovery of consciousness $(P<0.001)$ (Table 2). This significant increase was also noted for the subgroup of patients aged $\geq 65$ years after the initiation of sedation until recovery $(P<0.001)$ (Table 2$)$.

We detected a total of 13 incidences of significant cerebral desaturation $\left(>10 \%\right.$ decrease in $\left.\mathrm{rSO}_{2}\right)$ in 5 patients. The percentage of CDEs among all $\mathrm{rSO}_{2}$ measurements was $2.7 \%$. The lowest and highest BIS readings during these episodes were 63.5 and 85.5, respectively. Alternatively stated, CDEs occurred when patients were not under deep sedation anymore. No changes in these patients' hemodynamic and oxygenation parameters were noticed at the time of each CDE or within 5 min after. Interestingly, during lower levels of sedation (BIS values $<40,53$ of 480 BIS measurements) no CDE was recorded.

Regarding complications related to sedation, 2 cases of significant respiratory depression (decline in $\mathrm{SpO}_{2}$ to $<90 \%$ for more than $10 \mathrm{sec}$ ), 6 cases of hypotension ( $\mathrm{SBP} \leq 90 \mathrm{mmHg}$ ) and 4 cases of bradycardia (HR $<50$ beats/min) were noted in 12 patients during the procedure. Eight patients were aged $\geq 65$ years and 8 had a BMI of $25 \mathrm{~kg} / \mathrm{m}^{2}$ or more (range 27.2 31.9). Among these 12 patients, the most common medical comorbidities were as follows: hypertension (33\%), diabetes mellitus (16\%), congestive heart failure (16\%), and obstructive sleep apnea syndrome (8\%).

No substantial desaturation was recorded, neither at the time of the adverse events nor during the preceding and subsequent $\mathrm{rSO}_{2}$ measurements. All cases were treated successfully by the attending anesthesiologist. There were certain subjects with $\mathrm{rSO}_{2}<60 \%$ before propofol administration, but no sedationrelated complication was observed when these patients were examined separately.

\section{Discussion}

The current study indicates that cerebral oxygenation in patients deeply sedated with propofol exhibited little variability throughout sedation and remained independent of changes in sedation depth, irrespective of ERCP duration. Our literature search revealed no data on NIRS-based cerebral oximetry monitoring during ERCP, since the majority of data in this research field come from cardiac surgery.

Only a few reports in the literature have examined the relationship between cerebral oxygenation and changes in depth of sedation. In our study, no significant correlation was shown between the means of $\mathrm{BIS}$ and $\mathrm{rSO}_{2}$ measurements at

Table 2 Changes in partial pressure of carbon dioxide $\left(\mathrm{PaCO}_{2}\right)$

\begin{tabular}{lccc}
\hline $\mathrm{PaCO}_{2}$ & $\begin{array}{c}\text { Before } \\
\text { sedation }\end{array}$ & $\begin{array}{c}\text { During } \\
\text { sedation }\end{array}$ & $\begin{array}{c}\text { Recovery of } \\
\text { consciousness }\end{array}$ \\
\hline $\begin{array}{l}\mathrm{PaCO}_{2}(\mathrm{mmHg}) \text {, all } \\
\text { patients }(\mathrm{n}=60)\end{array}$ & $36.1 \pm 3.9$ & $44.7 \pm 7.6^{*}$ & $41.4 \pm 6.2^{*}$ \\
$\mathrm{PaCO}_{2}(\mathrm{mmHg})$, patients & $36.1 \pm 4.1$ & $45.8 \pm 7.7^{*}$ & $41.2 \pm 5.6^{*}$ \\
$\geq 65$ years $(\mathrm{n}=37)$ & & & \\
& & & \\
${ }^{*} \mathrm{P}<0.001$ vs. before sedation. Results are expressed as mean \pm standard \\
deviation
\end{tabular}

any time point of the procedure. Similar results were obtained when elderly patients ( $\geq 65$ years) were analyzed separately. In the same direction, Kanemaru et al. [19], in an attempt to examine whether BIS changes are mirrored by changes in cerebral oxygenation, investigated the effect of midazolam, isoflurane and aminophylline administration during general anesthesia with propofol. It was found that $\mathrm{rSO}_{2}$ recordings remained unchanged, although the 3 previously mentioned drugs significantly affected BIS values. Furthermore, a previous study by Fassoulaki et al. [20] reported that cerebral oxygenation remained constant when the depth of anesthesia was maintained at a steady state. Indeed, in our study, the depth of sedation exhibited little variation. Similarly, no CDE was recorded during unintended lower levels of sedation (BIS values $<40$ ).

Cerebral NIRS monitoring has been used to monitor cerebral perfusion and influence management in various perioperative settings: abdominal or orthopedic surgery [21,22], carotid endarterectomy [23], and aortic or cardiac surgery [24-28]. Several authors suggest that NIRS-based cerebral oximetry can reliably detect perioperative CDEs, particularly during cardiac surgery $[21,27,29-33]$. Other studies have also demonstrated the association between intraoperative CDEs and adverse neurological outcomes, postoperative cognitive dysfunction, major organ morbidity or mortality, and prolonged length of hospital stay $[27,34,35]$.

Baseline $\mathrm{rSO}_{2}$ values in our patients $(65.1 \pm 11.8 \%)$ were within the published normal range of $60-80 \%$ [16]. It is not clear what level of fall in $\mathrm{rSO}_{2}$ is significant, but according to previously published data, a fall in cerebral $\mathrm{rSO}_{2}$ of greater than $12 \%$ is a reliable ischemic "threshold" for brain ischemia, while a decrease in $\mathrm{rSO}_{2}$ greater than $20 \%$ from individual baseline is commonly considered as an intervention trigger during cardiac surgery [36]. Recognizing the fact that deep sedation maintains ventilatory function intact, providing less-secured airway management in a non-operating room compared with general anesthesia, and given that there is no existing data on cerebral oximetry monitoring among deeply sedated patients, we decided to apply a lower "threshold" $\mathrm{rSO}_{2}$ value to determine an episode of significant cerebral desaturation. Therefore, in our study, CDE was defined as any decrease in $\mathrm{rSO}_{2}$ greater than $10 \%$ of the baseline value.

The incidence of intraoperative decrease in cerebral oxygen saturation ranges from $30-70 \%$, depending on the definition of CDEs and the patient population [21,27,31,35]. In our study, the percentage of CDEs among all $\mathrm{rSO}_{2}$ measurements was $2.7 \%$, significantly lower when compared with the abovementioned published range. This may be due to differences in the targeted sedation level of these studies (deeper than in our study), types of surgery (neurosurgery, great vessel surgery, carotid endarterectomy, other surgery) and patients' individual conditions. While we anticipated that the rate would be lower compared with patients who underwent aortic or cardiac surgery, the very low CDE incidence was unexpected, given the lower "threshold" value adopted for our CDE definition.

Neither of our participants who experienced a CDE had a complication. Furthermore, none of the 12 patients who experienced a sedation-related complication recorded a 
decrease in $\mathrm{rSO}_{2}$ values $>10 \%$ of baseline value. Consequently, our observations suggest that $\mathrm{rSO}_{2}$ is not a predictor of changes in other organ systems of the body during propofolinduced deep sedation. In theory, a possible explanation may be provided by the presence of cerebral autoregulatory mechanisms. Cerebral autoregulation is a homeostatic process by which cerebral blood flow $(\mathrm{CBF})$ is maintained constant across a range of blood pressures [37]. An autoregulatory mechanism keeps CBF constant through vasodilation. Carbon dioxide in the arterial blood has a determinant effect on the cerebral arteriolar tone; in cases of hypercapnia, a dilation of the cerebral arterioles occurs, leading to increases in both $\mathrm{CBF}$ and cerebral blood volume [37]. Studies have shown that propofol preserves this autoregulatory response [38] better than other anesthetics $[38,39]$. Therefore, we assume that the significant increase observed among our patients in mean $\mathrm{PaCO}_{2}$ after the induction of sedation, in combination with the use of propofol, contributed to the maintenance of cerebral oximetry at a relatively steady value.

Cerebral oximetry has emerged as an encouraging noninvasive technology for brain monitoring. Nonetheless, we need to mention that variations in $\mathrm{rSO}_{2}$ values exist among different individuals, probably because of differences in skin color, sex, and arterial/venous ratios in the frontal lobe [36]. The interpretation of $\mathrm{rSO}_{2}$ values must be based on all clinical data, since pre-existing tissue dysfunction, carotid stenosis or incomplete circle of Willis may affect the perfusion of each hemisphere in a different way [40]. Bilateral $\mathrm{rSO}_{2}$ monitoring, as applied in our study, provides a greater chance of detecting unilateral disturbances of cerebral perfusion. The threshold value for clinically significant cerebral desaturation still remains unclear, and different studies have used different thresholds of $\mathrm{rSO}_{2}$ for interventions. Therefore, decision-making should be based on the clinical circumstances rather than the absolute $\mathrm{rSO}_{2}$ values. These restrictions have raised questions regarding the clinical utility of cerebral oximetry monitoring, indicating the need for new information regarding its incorporation in anesthetic practice.

The limitations of our study should be noted. First, it was an observational prospective study. Indeed, a randomized controlled trial would provide more reliable evidence; however, data are lacking and its design might not be feasible. Second, as this was an exploratory study, a sample size estimation was not deemed necessary. Considering the financial burden of a new technology which is not considered to be a standard of care, we preferred to carry out preliminary research in order to explore its clinical benefit among deeply sedated patients. Third, the depth of sedation was assessed with BIS monitoring, without the use of other validated clinical tools (e.g. the modified Observer's Assessment of Alertness/Sedation Scale). Because of legal restrictions, propofol sedation during ERCP procedures in our unit is always administered by an anesthesiologist, and the anesthesiology team of our institution has adopted BIS monitoring as the standard of care during total i.v. anesthesia. Nevertheless, given that the primary aim of our study was to evaluate how cerebral oxygenation is affected during propofolmediated deep sedation and since no previous research has been done, this study addresses an unanswered issue.
In conclusion, our results are highly suggestive that NIRSbased cerebral oxygenation monitoring is unlikely to influence the clinical management of patients deeply sedated during ERCP procedures, since CDEs had no clinical impact and did not provide an early indication of clinical deterioration. However, these results cannot be generalized and larger studies are needed to better define their clinical value. On the other hand, the fact that cerebral oxygenation remained stable and independent of changes in sedation depth, even at unintentional deeper levels of sedation, implies that propofolmediated sedation remains a safe practice as far as oxygenation in cerebral tissue is concerned.

\section{Summary Box}

\section{What is already known:}

- Propofol-induced deep sedation and general anesthesia represent the most common sedation practices for endoscopic retrograde cholangiopancreatography (ERCP) procedure at present time

- Optimizing sedation management significantly affects patient safety and procedure outcome

- Cerebral oximetry has emerged as an encouraging noninvasive technology for monitoring cerebral function during sedation by providing instantaneous information about the status of brain perfusion

- Previous studies in various perioperative settings under general anesthesia have shown that cerebral oximetry can reliably detect intraoperative adverse events and influence the treatment strategy

\section{What the new findings are:}

- This study is the first attempt to evaluate cerebral oximetry monitoring in non-intubated patients undergoing ERCP under propofol-induced sedation

- The results of the current study indicate that cerebral oxygenation remains independent of changes in sedation depth, irrespective of ERCP duration, and that cerebral oximetry monitoring is unlikely to provide an early indication of sedationrelated adverse events

\section{References}

1. Jeurnink SM, Steyerberg E, Kuipers E, Siersema P. The burden of endoscopic retrograde cholangiopancreatography (ERCP) performed with the patient under conscious sedation. Surg Endosc 2012;26:2213-2219.

2. Krugliak P, Ziff B, Rusabrov Y, Rosenthal A, Fich A, Gurman GM. Propofol versus midazolam for conscious sedation guided by processed EEG during endoscopic retrograde cholangiopancreatography: a prospective, randomized, doubleblind study. Endoscopy 2000;32:677-682. 
3. Riphaus A, Stergiou N, Wehrmann T. Sedation with propofol for routine ERCP in high-risk octogenarians: a randomized, controlled study. Am J Gastroenterol 2005;100:1957-1963.

4. Dumonceau JM, Riphaus A, Schreiber F, et al. Non-anesthesiologist administration of propofol for gastrointestinal endoscopy: European Society of Gastrointestinal Endoscopy, European Society of Gastroenterology and Endoscopy Nurses and Associates Guideline-Updated June 2015. Endoscopy 2015;47:1175-1189.

5. Valencia L, Rodríguez-Pérez A, Kühlmorgen B, Santana RY. Does sevoflurane preserve regional cerebral oxygen saturation measured by near-infrared spectroscopy better than propofol? Ann Fr Anesth Reanim 2014;33:e59-e65.

6. Ghosh A, Elwell C, Smith M. Review article: cerebral nearinfrared spectroscopy in adults: a work in progress. Anesth Analg 2012;115:1373-1383.

7. Naguib AN, Winch P, Ro PS, Olshove V, Tobias JD. Changes in near-infrared spectroscopy and the bispectral index during tilttable examination. Pediatr Cardiol 2011;32:234-236.

8. Schön J, Heringlake M, Berger KU, Volker Groesdonk H, Sedemund-Adib B, Paarmann H. Relationship between mixed venous oxygen saturation and regional cerebral oxygenation in awake, spontaneously breathing cardiac surgery patients. Minerva Anestesiol 2011;77:952-958.

9. Paarmann $\mathrm{H}$, Heringlake $\mathrm{M}$, Heinze $\mathrm{H}$, et al. Non-invasive cerebral oxygenation reflects mixed venous oxygen saturation during the varying haemodynamic conditions in patients undergoing transapical transcatheter aortic valve implantation. Interact Cardiovasc Thorac Surg 2012;14:268-272.

10. Paarmann H, Schön J, Schmidt W, et al. Agreement of noninvasive cerebral oxygenation with mixed venous oxygen saturation in patients undergoing ECMO-therapy. Appl Cardiopulm Pathophysiol 2011;15:55-61.

11. van Beest P, Wietasch G, Scheeren T, Spronk P, Kuiper M. Clinical review: use of venous oxygen saturations as a goal - a yet unfinished puzzle. Crit Care 2011;15:232.

12. Keats AS. The ASA classification of physical status-a recapitulation. Anesthesiology 1978;49:233-236.

13. Medical Advisory Secretariat. Bispectral index monitor: an evidence-based analysis. Ont Health Technol Assess Ser 2004;4:1-70.

14. Wehrmann T, Grotkamp J, Stergiou N, et al. Electroencephalogram monitoring facilitates sedation with propofol for routine ERCP: a randomized, controlled trial. Gastrointest Endosc 2002;56:817-824.

15. Paspatis GA, Chainaki I, Manolaraki MM, et al. Efficacy of bispectral index monitoring as an adjunct to propofol deep sedation for ERCP: a randomized controlled trial. Endoscopy 2009;41:1046-1051.

16. Tosh W, Patteril M. Cerebral oximetry. BJA Educ 2016;16:417-421.

17. Testoni PA, Mariani A, Aabakken L, et al. Papillary cannulation and sphincterotomy techniques at ERCP: European Society of Gastrointestinal Endoscopy (ESGE) Clinical Guideline. Endoscopy 2016;48:657-683.

18. Banks PA, Bollen TL, Dervenis C, et al.; Acute Pancreatitis Classification Working Group. Classification of acute pancreatitis-2012: revision of the Atlanta classification and definitions by international consensus. Gut 2013;62:102-111.

19. Kanemaru Y, Nishikawa K, Goto F. Bispectral index and regional cerebral oxygen saturation during propofol/N2O anesthesia. Can J Anaesth 2006;53:363-369.

20. Fassoulaki A, Kaliontzi H, Petropoulos G, Tsaroucha A. The effect of desflurane and sevoflurane on cerebral oximetry under steadystate conditions. Anesth Analg 2006;102:1830-1835.

21. Casati A, Fanelli G, Pietropaoli P, et al. Continuous monitoring of cerebral oxygen saturation in elderly patients undergoing major abdominal surgery minimizes brain exposure to potential hypoxia. Anesth Analg 2005;101:740-747.

22. Trafidło T, Gaszyński T, Gaszyński W, Nowakowska-Domagała K.
Intraoperative monitoring of cerebral NIRS oximetry leads to better postoperative cognitive performance: a pilot study. Int $J$ Surg 2015;16:23-30.

23. Zogogiannis ID, Iatrou CA, Lazarides MK, et al. Evaluation of an intraoperative algorithm based on near-infrared refracted spectroscopy monitoring, in the intraoperative decision for shunt placement, in patients undergoing carotid endarterectomy. Middle East J Anaesthesiol 2011;21:367-373.

24. Deschamps A, Lambert J, Couture P, et al. Reversal of decreases in cerebral saturation in high-risk cardiac surgery. J Cardiothorac Vasc Anesth 2013;27:1260-1266.

25. Deschamps A, Hall R, Grocott H, et al.; Canadian Perioperative Anesthesia Clinical Trials Group. Cerebral oximetry monitoring to maintain normal cerebral oxygen saturation during highrisk cardiac surgery: a randomized controlled feasibility trial. Anesthesiology 2016;124:826-836.

26. Harilall Y, Adam JK, Biccard BM, Reddi A. The effect of optimising cerebral tissue oxygen saturation on markers of neurological injury during coronary artery bypass graft surgery. Heart Lung Circ 2014;23:68-74.

27. Murkin JM, Adams SJ, Novick RJ, et al. Monitoring brain oxygen saturation during coronary bypass surgery: a randomized, prospective study. Anesth Analg 2007;104:51-58.

28. Vretzakis G, Georgopoulou S, Stamoulis K, et al. Monitoring of brain oxygen saturation (INVOS) in a protocol to direct blood transfusions during cardiac surgery: a prospective randomized clinical trial. J Cardiothorac Surg 2013;8:145.

29. Bhatia R, Hampton T, Malde S, et al. The application of nearinfrared oximetry to cerebral monitoring during aneurysm embolization: a comparison with intraprocedural angiography. J Neurosurg Anesthesiol 2007;19:97-104.

30. Egawa J, Kawaguchi M, Inoue S, Nishiwada T, Furuya H. Cerebral oxygen balance and postoperative cognitive function in patients undergoing lung surgery with one lung ventilation under propofol or sevoflurane anesthesia. J Neurosurg Anesthesiol 2009;21:408-409.

31. Greenberg SB, Murphy G, Alexander J, Fasanella R, Garcia A, Vender J. Cerebral desaturation events in the intensive care unit following cardiac surgery. J Crit Care 2013;28:270-276.

32. Lovell AT, Owen-Reece H, Elwell CE, Smith M, Goldstone JC. Continuous measurement of cerebral oxygenation by near infrared spectroscopy during induction of anesthesia. Anesth Analg 1999;88:554-558.

33. Moreno GE, Pilán ML, Manara C, et al. Regional venous oxygen saturation versus mixed venous saturation after paediatric cardiac surgery. Acta Anaesthesiol Scand 2013;57:373-379.

34. Vohra HA, Modi A, Ohri SK. Does use of intra-operative cerebral regional oxygen saturation monitoring during cardiac surgery lead to improved clinical outcomes? Interact Cardiovasc Thorac Surg 2009;9:318-322.

35. Yao FS, Tseng CC, Ho CY, Levin SK, Illner P. Cerebral oxygen desaturation is associated with early postoperative neuropsychological dysfunction in patients undergoing cardiac surgery. J Cardiothorac Vasc Anesth 2004;18:552-558.

36. Murkin JM, Arango M. Near-infrared spectroscopy as an index of brain and tissue oxygenation. Br J Anaesth 2009;103 Suppl 1:i3-i13.

37. Armstead WM. Cerebral blood flow autoregulation and dysautoregulation. Anesthesiol Clin 2016;34:465-477.

38. Strebel S, Lam AM, Matta B, Mayberg TS, Aaslid R, Newell DW. Dynamic and static cerebral autoregulation during isoflurane, desflurane, and propofol anesthesia. Anesthesiology 1995;83:66-76.

39. Dagal A, Lam AM. Cerebral autoregulation and anesthesia. Curr Opin Anaesthesiol 2009;22:547-552.

40. Vretzakis G, Georgopoulou S, Stamoulis K, et al. Cerebral oximetry in cardiac anesthesia. J Thorac Dis 2014;6(Suppl 1):S60-S69. 